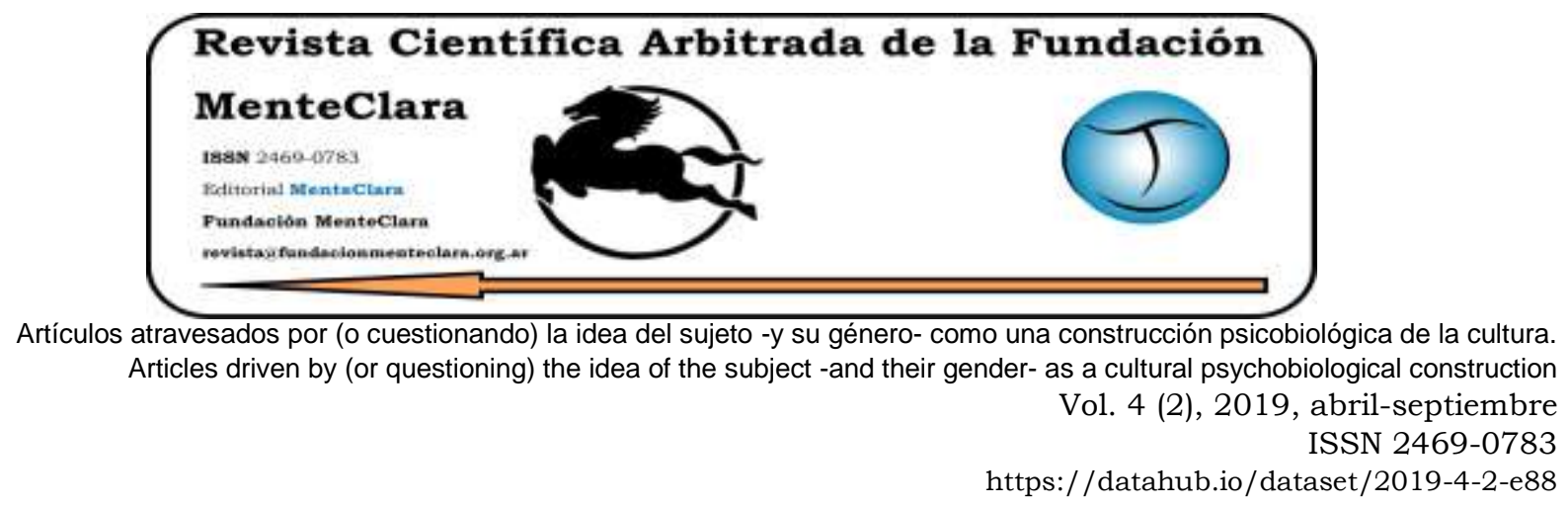

\title{
TRANSITIONAL SPACE: AN OPENING OF THE EXPERIENTIAL REALM BEYOND THE MIND
}

\author{
ESPACIO TRANSICIONAL: UNA APERTURA DEL REINO EXPERIMENTAL MÁS ALLÁ \\ DE LA MENTE
}

Rudolph Bauer rbauer@rsbauer.net

Center for Consciousness Studies and Washington Center for Phenomenological and Existential Psychotherapy Studies. United States of America

Cómo citar este artículo / Citation: Bauer R. (2019). "Transitional Space: An Opening of the Experiential Realm Beyond the Mind". Revista Cientifica Arbitrada de la Fundacion MenteClara, 4(2) abril-septiembre 2019, 167-201.

DOI: https://doi.org/10.32351/rca.v4.2.88

Copyright: (C) 2019 RCAFMC. Este artículo de acceso abierto es distribuido bajo los términos de la licencia Creative Commons Attribution 4.0 International License (CC BY 4.0). Recibido: 02/07/2019. Aceptado: 16/07/2019 Publicación online: 30/10/2019

Conflicto de intereses: None to declare.

\begin{abstract}
This article describes how Donald Winnicott's radical existential psychoanalytic understanding of transitional awareness and transitional relatedness intertwines both our personal psychology and our innermost experience of our own existential ontology. This article also addresses the ontological coincidences of our contemporary Existential Phenomenological understanding and Tantric Dzogchen praxis of the 8th and 9th century CE. The paper shows how 8th and 9th century CE Dzogchen Tantric understanding illuminates existentialist thinking through the transcendental phenomenology of Husserl and later ontological phenomenologist such as Heidegger and Merleau- Ponty. The paper also unfolds how these two modalities of existential phenomenological psychotherapy and tantric praxis converge in the experiential process of self liberation. The work also describes how in the patriarchal spiritual world, an experience of Being that is easily accessible has become something
\end{abstract}


belonging to a few "enlightened ones" in the form of a corporate product or brand. Some of the most hidden secrets of Tantra is herein presented.

\section{Resumen}

Este artículo describe cómo la comprensión psicoanalítica existencial radical de Donald Winnicott de la conciencia de transición y la relación de transición entrelaza nuestra psicología personal y nuestra experiencia más profunda de nuestra propia ontología existencial. Este artículo también aborda las coincidencias ontológicas de nuestra comprensión fenomenológica existencial contemporánea y la praxis tántrica Dzogchen de los siglos VIII y IX. El artículo muestra cómo la comprensión tántrica de Dzogchen CE de los siglos VIII y IX ilumina el pensamiento existencialista que atraviesa la fenomenología trascendental de Husserl y más tarde la fenomenología ontológica de Heidegger y Merleau-Ponty. El artículo también revela cómo estas dos modalidades de psicoterapia fenomenológica existencial y praxis tántrica convergen en el proceso experiencial de auto liberación. El trabajo también describe cómo una experiencia que es de fácil acceso se convirtió en el mundo espiritual patriarcal en algo propio de unos pocos "iluminados" como producto corporativo o marca ofreciendo, así, con este artículo, el más oculto secreto del tantra.

Keywords: Tantra; rigpa; awareness; transitional awareness; psychotherapy; phenomenological; existential; epoche; Dzogchen; Winnicot; Husserl; Jung

Palabras Claves: Tantra; rigpa; conciencia; conciencia transicional; psicoterápia; fenomenológica; existencial; epoché; Dzogchen; Winnicot; Husserl; Jung 


\section{Introduction}

Donald Winnicott's radical existential psychoanalytic understanding of transitional awareness and transitional relatedness is an amazing and little used doorway for today's psychotherapist and psychoanalyst. In today's cognitive clinical culture we have become cognitions tampering with cognitions. Life as cognition.

\section{Existential Ontology}

Winnicott's creative understanding of our capacity for transitional awareness and transitional relatedness intertwines both our personal psychology and our innermost experience of our own existential ontology. Transitional knowingness intertwines both our mind and our primordial awareness field. Our field of awareness knows the field of Being since awareness is the field of Being. Transitional awareness intertwines both our mind and our psyche (Winnicott, 2012).

Donald Winnicott's phenomenological understanding of the self radicalizes our sense of self from being a representational picture or cognitive affective schema or synthesis of disparate psychological part's to a fluid sense of self as a direct experiential felt sense of ongoing continuity of Being. Our knowingness though the medium of awareness, opens for us the direct knowing of the experience of Being. The experience of Being is for us our sense of natural spirituality. Our liminal transitional awareness field opens us into the immediate ongoing intimate experience of Being. This experience of Being is of Being within our very own self and of Being within our very own relational life-world. 


\section{Ordinary Personhood}

We, as a most ordinary person, can experience the unfolding movement of the experiencing of Being within our own self as our self, and simultaneously, the unfolding experiencing of our own being as the being-ness of Being which is the Being of the world. As we experience the Being of our world we simultaneously experience the luminosity of Being in and through the world itself. Being itself manifests as everything and anything. Being is pure potentiality.

This experiencing of the Being of our own being opens for us the experience of Being itself. Being itself is not a being. Being manifests and brings forth being in and as all beings. Our personal psychological anxiety and our veiled ontological insecurity are the same agony. The experience of the oblivion of Being is agony. The oblivion and absence of Being is the agony of annihilation and the agony of meaninglessness and lifelessness. The felt sense of non-Being is felt as meaningless lifelessness.

\section{Entering Transitional Awareness}

There is no one way of entering into transitional space of awareness. Often a person may be located in their mind alone or located in a particular function of the mind such as thinking, sensation, memory, imagination and feeling. Being located in mind as mind, the person makes a shift and becomes aware of their mind and the functions of their mind. There is a space of knowingness between their awareness and their mind. The person is now aware of their mind. This is mindfulness! To experience that we are not our mind is an amazing moment!

Next from within their awareness of mind, a person makes another shift in which they become aware no longer of their mind, but they 
become aware of their awareness itself. At this moment the person experiences awareness as their felt sense, their felt sense of their being as awareness. This becoming aware of awareness is entering into transitional awareness. The Existential Dzogchen tradition of Tibetan Buddhism calls this awareness of awareness Rigpa (Tulku, 1999). The rigpa tantric practice allows achieving consciousness devoid of dual conceptualizations of discursive nature (Yeshe, 1987) (Dalai Lama, 1994) or pre-notions, a priori judgments. A clinical trial observing biological indicators proved that "Rigpa meditation allows a practitioner to become aware of their own awareness to create an early warning system upon a negative impulsive action" (Gómez, 2017).

There are many ways of entering this liminal and intermediate space of awareness. There is no one way. Another of the ways of entering into transitional awareness is the way of phenomenology. In phenomenology, a person suspends their mind or suspends the judgmental function of their mind. Through our suspension of mind and the judgment of mind, our awareness is freed to become aware of awareness itself. We become free to gaze into the appearance of phenomena and experience directly and immediately, the luminosity of phenomena. This gazing opens for us the luminosity of appearance of phenomena. Our inner light of awareness perceives and sees through appearance and sees through phenomena into the luminosity of phenomena, into the light unto phenomena. This is the luminous spacious essence of phenomena!

\section{Epoche and Reduction}

What phenomenology calls the epoche and the reduction process goes like this. A person shifts from being located in the judgmental-ness of mind and then the person becomes aware of the mind. This is a form of 
mindfulness. This pause is also the epoche. The epoche is pause or suspension of mind. This suspension of judgment of mind is the epoche.

Then the person can make another shift. The person shifts from the person being aware of mind to the person becoming aware of awareness itself. This is the reduction in which one enters the awareness of awareness. In the reduction there is a turning towards or a turning inward. The focus is no longer on mind alone but the focus is on awareness itself.

This awareness of awareness is the transitional space of awareness. It is called transitional because this awareness is the intermediate area between personal mind and the existential field of awareness, the field of Being. Transitional awareness opens us to experience the field of Being. Transitional awareness is awareness in its transitional function. Transitional awareness allows one to bridge from being in the psychology of mind to being within the field of awareness that knows Being itself. Transitional awareness bridges the psychological mind experience and the ontological knowing experience of human existence. Transitional awareness bridges the knowingness of conceptual mind and the gnosis of direct knowingness. Transitional awareness bridges our knowing of duality and our knowing of non-duality.

\section{The Qualities of Transitional Awareness}

As we remain in this liminal space of becoming aware of awareness, the quality and nature of this transitional space begins to become manifest. The nature of this awareness manifests itself as spaciousness, as openness or as some eastern philosophical traditions say sunyata or emptiness (Norbu, 1989). Simultaneously, the manifestation of the quality of luminosity, or clarity or light or radiance self-manifest to us 
within this experiential knowingness. The energy of awareness also begins to manifest and the vitality and aliveness of this existential awareness field is experienced. In some eastern traditions this energy is called the Qi (Chinese) or the Shakti (Hindu) or Tiklay (Tibetan). The quality of this transitional awareness begins to expand throughout our body and beyond our body boundaries. We begin to experience our awareness as a field. We begin to experience our field of awareness as an existential field. Some cognitive psychologists refer to this phenomena as extended mind (Richard, 2007).

\section{Embodiment of the Existential Field}

As we continue to remain in this existential field we begin to embody this field of awareness. We embody the light of awareness. The existential field quality of this field of awareness becomes apparent and experientially unfolds. This existential field is ultimately infinite in its horizons and vast and multidimensional. The field is an unbound doorway of openness.

By becoming awareness of awareness we enter into the transitional space of awareness which is a perceptual field of knowing. In this perceptual field a person can still have access to their mind or aspects of their psychological mind. The person is now located in the field of awareness and no longer not solely in their mind. Being in awareness and by learning to remain in this space of awareness, the primordial qualities of the transitional realm become more explicit, clearer and become over time en-owned and embodied. Besides the qualities of spaciousness, of openness, of luminosity, of clearness, of the sense of subtle energy and of vital-ness, there arises simultaneously, the sense of oneness and 
indivisibleness which is the sense of non-duality. And most amazingly there arises the sense of purity.

\section{Purity}

Awareness is pure, awareness is always pure. Awareness within our Being is pure, completely pure, and awareness in others is always pure. The purity of awareness is the purity of Being. The purity of the openness of awareness is actually the openness of Being. Awareness knows Being and awareness is the knowingness of Being. The experience of the purity of awareness is freeing, and this purity dissolves affective states of mind. As we experience the purity of awareness within our own self, we can begin to experience the purity of awareness within others. We can resonate to the purity of awareness in others, despite their mind's closedness. The purity of awareness is not the psychological purity of mind or purity of character or even a kind of physical purity. Purity is not the purity of thought, or purity of feelings, or purity of desire, or purity of habits, or purity of behavior.

The purity of awareness is the experience of self-liberation. To feel the purity of your own awareness is to feel free. The luminous openness of purity is self-liberating. The purity of awareness metabolizes whatever is brought into this purity. The purity of awareness metabolizes experience.

Moreover, a person can extend their sense of purity of awareness into another person. A person within their own inner sense of the purity of awareness can resonant to the purity of inner awareness in another person. Again, this purity of awareness is not the same as the purity of mind. The mind is flooded by everything and anything. Mind and awareness are distinct. Mind is psychological, and awareness is ontological. Mind knows beings and awareness knows Being. 


\section{Compassion as Purity}

This is amazing. We can actuality extend our field of awareness into situations and into others. In mutuality we can extend our field to each other, and within each other. This meeting of the mutual extensions will increase the sense of indivisibleness and the experience of non-duality between the participants. This purity within awareness as awareness is the source of compassion. This is why the power of compassion is beyond our mind and its judgmental-ness. Compassion is beyond character and beyond ethical mental principles. Compassion is far beyond psychological empathy. Compassion is not within the psychological continuum of empathy. It is really useful to understand this difference. Most people think compassion is simply another word for empathy. Or wishing everyone well is not the essence of compassion. Compassion is not a wishing tree but a great and generous action.

Compassion arises out of the purity of awareness. The purity of awareness is naturally in resonance with the purity of awareness in others. Compassion resonates to and with the purity in everything and anything, and in everyone and anyone. Compassion is beyond prejudice. Pure Being-ness of being is the purity of all beings within Being. Compassion is always Pure.

Paradoxically, the purity of awareness can infuse our mind with clarity and clear perception. This infusion allows us to see into the character of situations, and into a person's character and even into groups of persons. Within the experiential level of the non-dual dimension of our own awareness, we can experience the purity of the being of the other, and within the level of dualistic mind we can perceive into the other's character as goodness and as evilness, as true and as false, as rightness and as wrongness. We can experience intent because our sense of awareness is in union with the mind, and awareness influences the 
perception of the mind. The lucidity of awareness infuses the lucidity of mind.

This purity of awareness is purity of Being. This purity is luminous spaciousness. This purity is potential space. And this the purity of Being is indestructible. To live within the purity of our Being is to experience our innermost sense of Being as unborn and undying. The foundational sense of annihilation anxiety and ontological agony becomes less and less organizing and less and less compelling. The fear of death begin dissolving into no-thingness.

\section{Innermost Being and Experience}

Since our transitional awareness is distinct from our mind, being in transitional awareness opens us into the second reduction which is becoming firmly located and established within this field of awareness of awareness. This experiential shift allows us to experience phenomena and the appearance of phenomena in a direct and unmediated fashion. This shift opens us to directly experience and directly know the field of Being.

The felt sense of the manifestation of this field of the experience of innermost awareness becomes vibrant and luminous. We simultaneously experience indivisibleness within our self and within the world of appearance. Our experience of the life world can have continuity and aliveness whatever the context and whatever the narrative.

There is the simultaneous experience of oneness and separateness. There is the sense of being within the duality of experience, and having the underlying experience of non-duality. Within the experience of nonduality we experience the unitary experience between subject and object, 
between us and others, and between us and source, between our being and Being itself.

Being established in this field of awareness of awareness offers us the feeling of being free of containment. This sense of being free is not incidental to being within this open luminous field of awareness. Being in transitional awareness offers the doorway into becoming aware of awareness itself. This awareness of awareness is the existential base which is not based on belief. The space of awareness becomes our experiential existential base. Our ground of awareness becomes our experiential existential ground of Being.

\section{Integration of Our Mind: A Necessity}

In the movements of this phenomenology of awareness we shift from being in mind alone to being in awareness of awareness. We begin to embody the experience of transitional awareness and its wonderful qualities. Once we have established our self within, and as transitional awareness, we then can take the step of integrating our mind into our field of awareness. This is an important and necessary step! We can begin to learn to think, and feel, and sense, and imagine and move within this transitional field of experiencing. We can begin to live in our life world within the transitional field with our minds integrated within the awareness field. We can begin to live within the field of awareness because we have integrated our mind into this awareness field. This integration of mind into awareness is completely important and supports us in experiencing the non-dualistic experience of indivisibility within the realm of duality of appearance and phenomena. 


\section{Heidegger's Da Sein and Transitional Space}

Transitional knowingness has rich similarity to Heidegger's understanding and presentation of Da Sein. For some Da Sein is spacious openness, the openness of awareness to primordial Being itself. This primordial openness is unbound spacious knowingness. This primordial there-ness is spaciousness or openness to what is being given through and by Being. Implied in this understanding of $\mathrm{Da}$ sein is the differentiation and distinction between mind and the openness of thereness, the openness of Da Sein. Da Sein is the human beings openness to Being itself. The oblivion and absence of the experience of Being is agony.

\section{Being There as Da Sein}

Our human openness is the openness of there-ness. Our mind is distinct from this foundational there-ness. The psychology of mind and functions of mind is distinct from Da Sein. Da Sein is the dimension of the human being as awareness that is open to Being itself, open to the given-ness of Being (Heidegger, 1958). This awareness is the same awareness of transitional space and transitional relatedness that we have been describing from Winnicott's psychoanalytic view of transitional relatedness to the field of Being and its manifestations. Through our relational openness to beings we are open to experiencing Being itself. All relational life is iconic. Sentient beings are iconic doorways into Being itself, as Being itself.

\section{Transitional Space and the Dimensions of Awareness}

The existential field of awareness is infinite in its horizon, vast and multidimensional. The field of awareness has three dimensions. The field of awareness is three dimensions. These dimensions are the realm of the 
ordinary life world, the realm of archetypal manifestations and the realm of pure potentiality. In tantric/existential Dzogchen language these dimensions are Nirmanakaya, Sambogakaya and Dharmakaya. Although distinct, these three dimensions are in essence indivisible and are in nondual oneness. Although distinct there is only one essence (Wallace, 2015).

Unhappily, many ancient and contemporary philosophical traditions and spiritual lineages lack this direct understanding or this direct experience that the three dimensions of the field of awareness although distinct are in essence indivisible and are in non-dual oneness. These various traditions are limited by their lack of the direct experience of the non-duality of the essence of awareness and the essence of phenomena. Their lack of experiential understanding invalidates their natural experience of the ordinary life world being the embodiment and manifestation of the light of primordial awareness. These lineages do not experience the natural liberation of duality within non duality and nonduality within duality. They think, they actually really think non-duality is separate from appearance of phenomena, separate from the ordinary life world. Some of these traditions think that the Nirmanakaya-ordinary life/ world- is not exactly the same essence as Dharmakaya-pure potentiality-. This lack of understanding is a source of much suffering. This limited and debilitating closed understanding is found in certain forms of Buddhism, Hinduism and Christianity. Their incomplete understanding is very sad and does not truly express the truth of the natural unfolding of the embodiment of the light. This is the natural unfolding of self -liberation in this life whatever the circumstances! This self- liberation takes place beyond belief or disbelief? 


\section{Remaining In Awareness}

As we remain in the spaciousness of transitional awareness this remaining opens for us the luminous experience of the manifestation of our ordinary life world in time-Nirmanakaya-. As we remain in the spaciousness of transitional awareness, we open into the experience of the manifestation of the archetypal dimension of our existence Sambogakaya-. And finally remaining within this transitional field of awareness opens for us the profound experience of the pure potentiality of becoming-Dharmakaya-.

Winnicott's work compliments the archetypal Jungian-Hillman-Tarnas endeavor of archetypal psychology and as well compliments the existential phenomenological orientation of the continental phenomenological tradition. Winnicott's work also opens the doorway to understand the Tibetan Existential Dzogchen tradition of the kayas, the multidimensional-ness of the existential field of awareness.

\section{From Transcendental to Immanence}

The understanding of transitional space gave the Jungian tradition and the archetypal psychoanalyst an understanding about the psychological place where archetypal experience manifest. At one time the Jungians thought that the archetypal was a transcendental experience and a transcendental phenomenon. As the understanding of transitional awareness, and transitional space unfolded within Jungian phenomenology, the earlier Kantian transcendental assumptions fell away. The understanding of the archetypal dimension changed from being a transcendental realm to being the realm of embodied immanence (Butler, 1987). Early Jung was captivated by Kantian transcendental preoccupation. Many esoteric adherents suffer from this sad fate of 
transcendentalism. Transcendentalism is an as if phenomena that experiences the life world as "as if". "As if" is "As if". All is pretend and fantasy!

The Jungian analytic understanding of archetypal reality transformed from the ancient understanding that archetypal reality is a transcendental reality and unfolded into the understanding that the archetypal dimension is within the dimension of immanence and is within our experience of the immanence of awareness. The immanence of awareness is an embodied experience. Rosemary Gordon's work was focal in bringing forth this understanding of transitional awareness into the Jungian/ Archetypal experience (Gordon, 2018). Contemporary archetypal psychology is a psychology of immanence. The archetypal experience is understood as the manifestation of cosmological psyche into personal psychology. Transitional awareness is the doorway of the archetypal dimension into human mind. Archetypal apparitions manifest within transitional space of awareness (Jung, 1959).

The contemporary Shavite master Swami Mutkananda often would say the "God dwells within you as you". Liberation happens through embodiment, through immanence! Most forms of the existential phenomenological tradition express the actuality of transitional space being the place of manifestation and knowingness of archetypal Being.

\section{Field of Being}

Winnicott's phenomenological psychoanalytic understanding presents a sequential developmental multidimensional experience of human beings. We begin with the understanding and the experience that our human mind is the ego and our mind is the ego functions of thinking, feeling, sensation, memory, imagination. We can make the personal shift 
from being in our ego/mind alone into the self-liberation opening of awareness. The person from being contained in their ego mind alone, can learn to shift into transitional space of open awareness. Rather than being only aware of their mind and the functions of our mind, the person enters into the awareness of the field of awareness. This transitional space opens us to experience of the existential field of Being whose qualities are spaciousness, vital-ness, non-conceptual illuminative knowingness. This illuminative knowingness is the direct knowingness of our experience of Being within our self and the direct experience of Being within others and through others.

Many religions mythologize our capacity for transitional awareness and religions often takes possession and make this natural human capacity of awareness as their own possession and spiritual invention. Religions tend to make the ordinary knowingness both of our mind and our awareness field as special or an exceptional religious event. This religious elaboration can makes this natural experience distant and special or rare or even worst supernatural. Through religious elaboration this most natural experience becomes a corporate product and brand name.

\section{An Essential Understanding! One Knower and the Two Forms of Knowing: Duality and Non Duality}

We have two ways of knowing. Our mind knows beings, forms and things, both subtle and gross. Our mind knows faces, hands, buildings, trees, math formulas. Our awareness knows Being. Our mind knows dualities. The mind knows you and me, us and them, and this and that. Our awareness knows non-duality. Our awareness knows Being directly and awareness knows the Being-ness of beings directly. Being is not a 
being and Being manifest beings. Being manifests Being, within beings, as their Being (Bauer, 2019).

Our mind knows an I and a you. Our mind knows a subject and an object. Our mind knows difference. Our awareness knows the indivisibleness and underlying oneness of phenomena. Our mind knows time, the past, the present and the future. Our awareness know timelessness in time and beyond time. Our mind is mediated conceptual knowing and our awareness is direct non-conceptual knowingness. Our mind is representational knowing, and our awareness is nonrepresentational knowing.

Our mind knows beings and things and our awareness knows Being. Being is not an entity, not a being. Being is non-dualistic. Being knows the non- duality of everything and anything. The capacity of our awareness for directly knowing Being in some philosophical traditions is called gnosis. Being is oneness and is pervasiveness. Being is openness. Being is radiance. Being self-manifests as radiant light and Being is compassionate and creative resonance. Being is no thingness, and manifests everything and anything.

Being manifest dualities, although Being is completely non-dual. By becoming aware of awareness, we experience primordial awareness which is the ground of beings, which is Being. Awareness is Being knowing itself. Being knows Being and the Being-ness of all the beings. Awareness can be timeless as well as manifesting beings in time as time.

Being manifest many dimensions. Being manifest the ordinary life world to use Husserl language and to use existential Dzogchen language Being manifests the Nirmanakaya. Being manifests the appearance and the disappearance of beings as this world. Being manifests the archetypal realm which are the elementals becoming forms of light and the light of 
forms. In existential Dzogchen this is the luminous Sambogakaya realm. Being is pure potentiality that brings forth everything and everything. Being always remains, since Being is timelessness. Being, to use the existential Dzogchen language is the Dharmakaya. This is the realm of timeless potentiality. This is the ground of Being. This is source. Timeless manifests in time, as time. Being manifests in time as beings. And all beings dissolve back into Being. Being reappears in time as beings who are Being itself re-manifesting as a being.

\section{Realm of the Life World Dimension}

We can and must integrate our mind and awareness within the realm of the ordinary life world of everyday-ness. We can integrate our knowing of duality of beings within the knowing of non-duality of Being. Within the knowing of the non-duality of Being we can integrate the knowing of duality of beings. For example when we shift our attention from our mind into the openness of the day as we walk down the street into the field of awareness both in us and around us, we take in the what is seen and experienced in a most natural way. We integrate what is seen into the non-duality of the field. We can integrate our knowing of beings and things, within our knowingness of Being. We can integrate our mind of meditated conceptual knowing into this transitional spacious awareness of direct knowingness. This integration liberates us from being located in mind alone. This integration of mind within the transitional awareness field is amazing and natural.

In mind alone we can know only within the duality of subject and object. In being in awareness only, we know Being alone without beings. By being in mind alone we experience dualistic experience alone without the simultaneous experience of non-duality. And by being in awareness 
alone without mind, we experience non-duality of Being without the simultaneous experience of the duality of beings. Either of these positions alone is existentially incomplete. Many so called non-dual spiritual traditions foreclosed the singularity of beings. They foreclose the natural liberation of knowing duality within non-duality and non-duality within duality. They miss the power of incarnation, the power of the embodiment of luminous awareness.

\section{Simultaneous Knowing}

When we integrate our mind within our awareness we are able to know beings and Being simultaneously. We know beings within Being and we know Being within beings simultaneously. We know duality and nonduality simultaneously. This is space of natural liberation.

Liberation from being locked in mind alone is completely possible for everyone. So as an ordinary person we can think and feel and live within the field of Being. Within their own being a person can experience Being itself. Within our own personal being we can experiences Being itself since our personal being is the manifestation of Being itself. Through the personal being of another person's being we can experience Being itself. When we experience Being itself, we experience the non-duality of Being. Through our relational duality with beings we can experience the nonduality of Being within us and between us. We can experience beings within the non-duality of Being and within the non-duality of Being we can experience the duality of beings. Duality is a doorway into Being.

As the Dakini said to the Dzogchen Master Dudjom Lingpa "You and I are indivisible". There is "a you" and there is "an I", this is duality. And there is our indivisibleness -non-duality-. From our being in the life world we can experience Being as the life world. In relational life we can know 
a person dualistically and non-dualistically simultaneously. We can experience oneness and difference simultaneously. Mind knows difference, and transitional awareness knows oneness or indivisibleness.

\section{The Mysterious Conjunction}

When mind and awareness conjoin, we can know individual being and through the individual being we can know Being itself. By knowing the individual being we know duality, and by knowing Being within the individual being we know non-duality. Through the Mysterious Conjunction of our mind and awareness we can know non-duality within duality and within duality we can know non-duality. As the Shavite master Swami Muktananda would so often declare "The bliss of Samadhi is the bliss of the world".

\section{The Life World Opens into Realm of the Archetypal Dimension}

Because of our integration of our mind into the experiential realm of transitional awareness, we can experience the unfolding of the profound opening within us that enables us to experience the manifestation of the archetypal dimension of human experience. This archetypal manifestation is not through the mental conceptual representation of mind, but through the doorway of transitional awareness. We now have an opening to experience the manifestation of the luminous, apparitional, archetypal dimension of human existence. This archetypal dimension is the archetypal cosmological realm of the luminous energies and forms reflecting the cosmological powers that manifest both our mind and life world circumstances. This apparitional dimension is like lucid dreaming and the apparitions are often mythological metaphors and dramas. 
Winnicott's own archetypal interest was in the masculine and female archetypal aspects of every personality.

Similar to Jung, Winnicott considers archetypal energies or forms to be central as formative in this dimension of human experience. In Jungian language this is the animus and anima dimension. Winnicott's understanding of psyche as transitional space also opens for the Jungians a place or a locus or opening for the archetypal realm to become visible and manifest as apparitional experience. This opening is not in mind alone but is the opening of and within transitional awareness, so that the vast depth of the realm of psyche can manifest into our mind and beyond mind. The archetypal realm is this luminous dimension of becoming. The archetypal dimension is the luminous energetic dimension becoming the life world. The luminous elemental energies become forms and luminous fields of light which self-manifest as the ordinary life world. In existential Dzogchen language the Sambogakaya dimension manifests the Nirmanakaya dimension of existence.

\section{Timeless Awareness within Transitional Awareness}

Within the depth of transitional awareness there is the timeless awareness dimension of human experience. A person can be in timeless awareness and in time at the same time. This timeless dimension unfolds and self-manifests as the archetypal dimension of existence. Timeless awareness becomes visible and apparitional as the archetypal realm. Timeless awareness manifests as mythic experience, mythic coded expression not unlike the lucid dream. There are many codes for the archetypal dimension, such as dreams, apparitions, visions, luminous energies and fields of light forms, metaphors of gods and goddesses, 
dakini and devas, and archetypal planetary energy and cosmology to name some of the metaphors.

\section{Collective Unconsciousness}

Jung would describe these metaphorical manifestations as the collective unconsciousness. The collective unconsciousness reflects the unfolding nature of Being and Cosmology and not simply human memory. The collective unconsciousness is not simply collective memory but collective ontological and cosmological experience becoming expressed in the present moment.

\section{The Realm of Potential Space}

Within the depth of transitional awareness there is the timeless awareness dimension of human experience. This timeless awareness is the pre- conceptual dimension of potential space. This realm of timeless awareness is primordial potential space that manifests everything and anything including our own personal awareness. This is the realm of pure creativity and pure potentiality. This is the also the realm of pure Being. This pure Being is not a being. This pure "no thingness" manifests everything and anything. Potential space is pure. Potential space is timeless awareness. To experience timeless awareness is to experience potential space. Even in the present moment, even right now!

In the language of existential Dzogchen this timeless awareness is the Dharmakaya. To experience potential space is to experience the Dharmakaya. There is an invocation in existential Dzogchen that says "grant us the single blessing to realize that all appearance are the Dharmakaya". This means that all phenomena and all appearance are the self- 
manifestation of pure potentiality. There is no essential difference between phenomena and the very essence of potentiality.

The Dzogchen Tibetan master Dudjom Lingpa describes Tibetan Dzogchen training as the training to experience the purity of all phenomena.

This potential space both manifests the existential field and manifests within the existential field as the phenomena of the ordinary life world. Potentiality manifests the existential field and manifests within the existential field as the archetypal dimension. The primordial existential realm of pure potentiality is pervasive and this pure potentiality is within everything and anything, within anyone and everyone. This is the potentiality which is the essence of phenomena, this is essence of appearance whatever the form or character of the appearance.

Pure potentiality is the indeterminacy of timeless awareness. Timeless awareness is the pure potentiality of indeterminateness manifesting within the archetypal dimension and manifesting within the phenomena of life world and manifesting within a person as their own awareness, manifesting as transitional awareness within you and within me.

\section{Timelessness Awareness Manifesting within Time: The Ontology of Change!}

Change is a moment of timelessness. Change is a moment of timeless awareness entering time and space. Timeless awareness is pure potentiality manifesting time and manifesting within time. Timeless awareness is pure indeterminateness manifesting within the space of time and place. Timeless awareness is potential space as indeterminacy entering time and situation. Timeless awareness is potential space as indeterminacy entering into fixated states of mind and situation within 
time and within space. Timeless awareness is movement and stillness simultaneously. Potential space is continuously becoming actuality, continuously becoming the Real. Potential space both destroys, brings forth and completes.

\section{Invocation}

Within the experience of timeless awareness in time, the power of invocation can take place and invocation can manifest the power of pure potentiality. Invocation is the power to call forth, the power to bring forth, the power to actualize potentiality. By entering into pure potentiality, we can invoke pure potentiality. A person who accomplishes the power of invocation is able and capable to bring forth the power of potential movement in the realm of the life world and to bring forth the power of potential movement into the archetypal realm. The power of invocation can manifest in each dimension of the existential field.

The power of invocation is within the life world and the phenomena of the life world. The power of invocation is within the archetypal realm and the phenomena of the archetypal realm. The power of the invocation is within the realm of pure potentiality. Moreover, the power of the archetypal dimension can be invoked and brought forth into the dimension of the life world. The life world can integrate and assimilate the power of the archetypal realm. This assimilation can be transformative within the life world and within our own life and within our own being, and within our own awareness field and the awareness of those we love.

The power of pure potentiality can be invoked and attuned to and brought forth into the archetypal realm and into the life world realm. The power of the pure potentiality can be invoked within each existential 
dimension. This power of potentiality is located deeply within our own innate innermost awareness. St. Augustine called it the "great deep". The actual power of potentiality is the power of the total field within us as us. The power of potentiality is within our innermost awareness as timelessness awareness. To enter into this dimension of pure potentiality is self-liberation. This potentiality is complete within each of the dimensions of the existential field. There is the power of self-liberation within the life world and within self.

\section{Existential Psychotherapy and the Existential Field Dimensions}

Existential psychotherapy focuses the therapeutic experience and therapeutic potential within the different dimensions of the existential field of human existence.

The Life World. The existential field dimension of the life world may initially be experienced as objectified interpersonal functional realm of experience. Then with the opening of transitional awareness within the existential field of the of life world, the life world becomes potential space for the intimate non-dual / dual relational realm of person to person, of inside to inside, of self to self, of subject to subject encounter within the transitional space of direct relatedness. This direct relatedness is true inter-subjectivity, this direct relatedness is inside to inside. This direct relatedness arises as the liberating non-dual experience within the duality of "a me" and "a you".

The therapeutic healing within the existential field takes place in the dual and non-dual experience of authentic inter-subjectivity. Subjectivity means the sense of awareness as "aham" meaning "I am". The sense of I am and the sense of you are, the sense of us being indivisible in this 
ongoing continuity of Being is self-liberation. You are and I am are in the continuity of indivisibleness of Being. There is the dualistic experience of "a you" are and of an "I am" and there is our non-dual indivisibility, our ongoing continuity of oneness simultaneously. This experience is innately healing and liberating. Through the immediacy of non-dual relational life we experience liberation within the field of Being as the field of Being.

This existential experience of duality within non-duality and nonduality within duality is the experience of self-liberation that brings forth foundational change. Experientially this takes place within the immanence of humanness and not the dissociative distancing of transcendental-ness. This is the natural spirituality that is beyond religion and beyond culturally fixated political patriarchal-ness and political fixated theocratic-ness. This is liberation through the potentiality within phenomena and potentiality within the appearance of phenomena. Within our experience of our indivisibleness with phenomena, we experience the liberating potentiality within phenomena. We experience Being as phenomena and Being through phenomena.

Archetypal Realm. This existential field of the archetypal realm opens the subtle relational drama of luminous archetypal forms and luminous energies and luminous forces. This apparitional experience brings us into the pre-personal sources of personal relational life. This pre-personal source is the pure potentiality within archetypal forms and formulations. These cosmological archetypal fields can be experienced and integrated and absorbed into relational life of our ordinary life world. Through the openness of transitional awareness the power and the vital energy of the archetypal fields can be brought forth within transitional awareness, and these same forces and fields can be assimilated within our personal awareness within our life world. 
Our subtle magnetic attunement to the archetypal forms and luminous fields of energy can bring forth within us the sense of luminous vital forms that open the vast cosmological range of human experience. These forms are beyond the mind and yet manifest within, and through our mind and our embodiment. These archetypal luminous fields can infuse our mind and our circumstances. This is liberation through luminous cosmology.

\section{Pure Potentiality as Source}

The existential field of primordial pure potentiality is both source and ground and can be experience in and of itself. To enter into pure potentiality is to become pure potentiality. This is self-liberation through pure potentiality. In this realm a person exists in potentiality as pure resonance. This potentiality is the potentiality of becoming; the potentiality for becoming actual, and for becoming actuality. Pure potentiality is pure knowingness as pure Being-ness. In this pure potentiality of everything and anything, you and I are the pure potentiality of becoming everything and anything including you and including me. This is liberation through the pure potentiality of timeless knowingness and the pure potentiality of timeless resonance. This power of pure potentiality manifests in the archetypal dimension and manifests within the life world dimension.

The existential field of primordial pure potentiality is source and ground of both the existential fields of the archetypal realm and the realm of ordinary life world. This primordial pure potentiality permeates with completeness all the existential fields. This existential field of primordial pure potentiality self- manifests as the archetypal dimension and selfmanifests as the life world. Most amazingly this existential field of pure 
potentiality permeates with completeness our own personal field of innermost awareness itself. Within the knower, there is knowingness as Being. Not simply knowingness as a being but as Being itself.

Our very own awareness as knowingness is the self-manifestation of pure potentiality as source. This is the mystery of our own ever present indivisibleness with pure potentiality. This is the ongoing mystery of our individual awareness being the manifestation of primordial awareness itself. This is the mystery of our own singular being, Being the manifestation of Being itself. This is the mystery of our actuality in time and space. Being is the manifestation of pure potentiality as pure potentiality. Being is pure potentiality in becoming-ness. Within our own personal awareness, timeless awareness and time are in complete union. This union of timelessness awareness within time, and time within timeless awareness is the power of self-liberation. Liberation can take place within our simultaneous experience of timelessness within time and time within timelessness.

Of course, this power of pure potentiality is foreclosed when we are in mind alone. This power of pure potentiality is foreclosed when we are in personal mind alone and when we are locked within institutionalized cultural mind alone. Institutionalized cultural mind can forecloses selfliberation as Maurice Merleau-Ponty describes in his famous text "Institutionalization and Passivity" based on course notes for classes taught at the Bibliothèque Nationale de Paris between 1954 and 1955.

To experience the power of invocation and the power of potentiality we can enter into the existential field as the field. We cannot be simply in the field, or knowing the field from mind alone. We can be the existential field knowing the field as our own self. This is natural liberation as the field. We can experientially become the field. This field is the ongoing continuity of Being. There is this simple unfolding process of knowing the field, then 
being in the field and then becoming field. As the great mantra Aham Ah declares, "I am becoming who I am".

\section{Existential Dzogchen}

In Existential Dzogchen there is this expression the "Dharmakaya is found within the experience of phenomena". There is also another statement in the Tantra "Everything is Light" that goes like this. "The open dimension awakens in open appearance". "The sole holistic sphere of Dharmakaya blends with the undivided field of appearance into an elixir that shines like sunlight in the sky". These words of this $10^{\text {th }}$ century Tantra of Everything is Light describes what we have been illuminating phenomenologically throughout this essay on transitional awareness.

\section{Further Aspects of Clinical Focus within the Power of Transitional}

\section{Awareness - Embodiment}

The clinical implications of transitional awareness is often focused on the unfolding transformation from dissociation and fragmentation within human experience to the unfolding of an embodiment of a cohesive sense of being itself. Liberation is an embodying experience. This embodiment is the embodiment of Being and the vitality of Being within us and within our environment. This embodiment is the embodiment of the Luminosity of Awareness as Being. This embodiment results in self-agency and selfregulation. This embodiment is the embodiment of transitional awareness, transitional space. This is the embodiment of mind and functions of mind within transitional space. And this is the embodiment of the body within the luminosity of the field of awareness of awareness, Rigpa. 


\section{Self-Regulation as Attunement to the Being of a being}

Within the existential understanding of transitional awareness, the understanding of self-regulation differs radically from the traditional psychoanalytic view of self-regulation as psychoanalytic formulations often requiring affective discharge and or sexual discharge (Lacan, 2018). Within the experience of awareness of awareness the emphasis is selfregulation through attunement to Being within our own being and attunement to the Being of another's being which is ultimately Being itself. This existential understanding integrates the experience of Being as intrinsic to human existence. The experience of Being as intrinsic to human existing-ness takes us beyond the polarity of mechanistic realism and 'as if' idealism (Hillman, 1992).

\section{Vital-ness}

Throughout Winnicott's work his emphasis is consistently on vitality or vital-ness. The essential understanding is that our sense of vital-ness and aliveness is our simultaneous experience of human being-ness and human actual-ness. This is the non -conceptual meaning of human growth and the non-conceptual sense of experiential embodiment. The sense of the embodiment of awareness as embodied Being is vital-ness or vitality.

The sense of vital-ness or vitality is a sublime indicator of embodied sense of self and embodied sense of ongoing continuity of Being. Vitalness is the source of self-agency. Vital-ness is the source of desire. Vitalness is the source of non-conceptual meaning. The unfolding of vital-ness is the source of action. Vital-ness is the source of the power of invocation. 


\section{Vitality and Attunement}

Our attunement to fundamental potentiality will bring forth vitality within ourselves and others. This fundamental potentiality is within everyone. And our own attunement to this potentiality within ourselves allows us to be attuned to this potentiality within the other. This attunement to the potentiality within the other can bring forth the vitalness within ourselves through resonance. We self-regulate through resonance to this potentiality within us and within everyone. This potentiality is the potentiality of Being itself which is awareness itself as us. This is also the pervasive potentiality within nature and the pervasive potentiality within the universe itself. So a person as ordinary person can be attuned to the potentiality of nature and the potentiality within the universe. Vital-ness is brought forth through this vast Indra's net ${ }^{1}$. Existence itself is potentiality in resonance. Human existence itself is potentiality in resonance.

\section{Intertwining of psychology and ontology as Potential Space}

This view of Winnicott opens in depth and breathe the capacity of potential space to bring forth change both in the psychological realm as well as the spiritual realm. Spiritual in this context simply means the Being realm. These existential realms are manifestation of the nonduality of psychology and spirituality. There is non-duality of the intertwining of psychology and ontology. This is an intertwining of mind

\footnotetext{
${ }^{1}$ Indra's net (also called Indra's jewels or Indra's pearls, Sanskrit Indrajāla) is a metaphor used to illustrate the concepts of Sünyatā (emptiness), pratityasamutpāda (dependent origination, and interpenetration) in Buddhist philosophy. The metaphor's earliest known reference is found in the Atharva Veda. It was developed by the Mahayana school in the 3rd century Avatamsaka Sutra and later by the Huayan School between the 6th and 8th centuries.

In Gödel, Escher, Bach (1979), Douglas Hofstadter uses Indra's net as a metaphor for the complex interconnected networks formed by relationships between objects in a system-including social networks, the interactions of particles, and the "symbols" that stand for ideas in a brain or intelligent computer.
} 
and transitional awareness. This is the intertwining of mind and psyche that you are and I am. This is the integration of the knowingness of mind and the knowingness of Being.

\section{Instinctual Driven-ness, Instinctual Dissociation, and Instinctual Sublimation}

Instinctual sublimation is a focus that can take place when we can live within the liminality of transitional knowingness. And rather than dealing with instinctual driven-ness by either repression, or foreclosure or dissociation, we learn to integrate this instinctual driven-ness into transitional awareness itself. Often a person can be caught in-between either being dissociated from instinctual driven-ness with consequent loss of vitality or completely possessed by instinctual drives, with consequent relentless impulsive discharge. In both context the instinctual movement and impulse is not integrated into the embodied field of innermost luminous awareness.

A person can be caught between the relentless discharge of drivenness such as sexual driven-ness or affective driven-ness as a way of modifying self-dysregulation. Discharge is the mode people often use to self-regulate psychological and biological stress. There are many and multiple modes of discharging. Sexual discharge, affect discharge, obsessive compulsive behavior discharging anxiety, food consumption as method of discharge, drug addiction, high risk behavior, compulsive religious ritualistic activity, relentless self- punishment and self-infliction of pain on others are some of the ways of utilizing discharge as a self regulation modality.

In the context of the dissociated sexual instinct, the dissociated sexual instinct can be integrated into the embodiment of transitional awareness. 
The actual deadness or blankness or absence of Eros can be integrated into transitional awareness. Moreover as the dissociated experience is integrated into transitional awareness, the vital-ness of the field infuses the dissociated instinctual sexual vital energies. Likewise the impulsive sexual driven-ness can be also integrated within luminous transitional awareness. Transitional awareness metabolizes and integrates the erotic life force within the innermost field of luminous awareness. This integration of the erotic instinct metabolizes the energy of the life force and becomes and infuses the innate field of embodied awareness.

\section{Conclusion}

As a person integrates their instinctual impulses into the field of innate luminous awareness the person may begin to experience selfregulation through the attunement of their awareness to the field of Being within themselves and to the field of Being within others and to the field of Being itself.

The metaphor of kundalini is a metaphor that signifies this gradual unfolding experience of integrating the various instinctual powers into our embodied light of awareness, into the embodied sense of self. This integration brings forth an embodied sense of vitality and empowerment without the agitation of dissociative emptiness or impulsive driven-ness.

The accomplishment of sublimation allows a person to self-regulate through attunement to the field of Being, and integrate the power of the instinctual vital life force within the light of the embodied field of awareness, which is the embodied field of Being itself.

Sublimation of the sexual instinct allows a person to have discrimination as to whom they desire to sexualize. Sublimation supports the self-arising of discrimination of sexual object choice. Sublimation can 
help a person become less bound and dominated from their relentless instinctual driven-ness for compulsive relentless sexual discharge. The relentless driven-ness of infused sexualized discharge is often a way to self-regulate psychological dysregulation and anxiety.

Sublimation also supports the sexualized instinctual-ness to become embodied in the innermost heart essence of awareness. The result of this embodiment within the inner most heat essence of awareness is that love can encompass sexual-ness and love can metabolize and transform the sexual driven-ness into attunement. Love subsumes Eros. Love illuminates Eros. Eros is integrated into the existential field of Being. Sublimation brings the instinctual sexualized energy into the luminous inner heart essence. The inner heart essence is the source of awareness and the metabolizing of primitive instinctual experience. The inner heart essence is the source of the metabolism of Eros within the light of awareness, within the embodiment of transitional awareness. This is the true secret of Tantra. This is self-liberation through embodiment. 


\section{References}

Bauer, R. (2019). "Mind As Knower of Forms, And Awareness as The Knower of Being: A Phenomenological View». Revista Científica Arbitrada de la Fundación MenteClara, 4(2) abril-septiembre 2019, 47-53. DOI: https://doi.org/10.32351/rca.v4.2.86 Read here

Butler, J.P. (1987) Subjects of Desire: Hegelian Reflections in Twentieth-Century France. New York: Columbia University Press.

Dalai Lama \& HOPKINS, J. (1999). Kalachakra Tantra: Rite of Initiation. Wisdom Publications.

Gómez, O. R. (2017). "Tantra o Yoga. Estudios clínicos, 2 ${ }^{a}$ parte: Tantra». Revista Científica Arbitrada de la Fundación MenteClara, 2(2), 85-116. DOI: https://doi.org/10.32351/rca.v2.2.31 Read here

Gordon, R. (2018). Dying and Creating: A Search for Meaning. Routledge.

Heidegger, M., \& Kluback, W. (1958). The question of being. New York: Twayne.

Hillman, J. (1992). Re-Visioning Psychology, Perennial.

Jung, C. (1959). The Archetypes of The Collective Unconscious, Bollingen Series XX, Princeton University Press.

Lacan, J. (2018). The Four Fundamental Concepts of Psychoanalysis, Trans. Alan Sheridan. New York: Norton.

Norbu, N. (1989). Dzogchen: the Self-Perfected State. London: Arkana.

Richard, T. (2007). Cosmos and Psyche. A Plume Book, New York, USA.

Tulku, U. R. (1999) As it is. Hong Kong: Ranjung Yeshe Publications.

Wallace, B. A. (2015). Dudjom Lingpa's Visions of the Great Perfection, Vol 3. The Vajra Essence. Wisdom Publications.

Winnicott, D. W. (2012). Playing and reality. Routledge.

Yeshe, T. (1987) Introduction to Tantra: A Vision of Totality. Wisdom Publications. 